\title{
Treatment of Supraophthalmic Internal Carotid Artery Fenestration with an Associated Aneurysm via Flow Diversion: A Case Report
}

\author{
Johannes Kasper (D) \\ Ulf Nestler (D) \\ Jürgen Meixensberger ${ }^{\prime}$ \\ Ulf Quäschling ${ }^{2}$ \\ 'Department of Neurosurgery, \\ University Hospital Leipzig, Leipzig, \\ 04103, Germany; ${ }^{2}$ Institute of \\ Neuroradiology, Department of \\ Diagnostic Medicine, University Hospital \\ Leipzig, Leipzig, 04103, Germany
}

Correspondence: Johannes Kasper Department of Neurosurgery, University Hospital Leipzig, Liebigstraße 20, Leipzig,

04103, Germany

$\mathrm{Tel}+493419717892$

Fax +49 3419717509

Email Johannes.Kasper@medizin.uni-

leipzig.de

\begin{abstract}
Cerebral artery fenestration with flow-associated aneurysm is rare among cerebrovascular pathologies. Treatment includes open neurosurgery and/or endovascular treatment. We report a case of a 53-year-old woman with an incidentally detected aneurysm during magnetic resonance tomography. As the underlying cause, a digital subtraction angiography revealed a left internal carotid artery fenestration. Elective endovascular treatment via flow diversion was indicated and a pipeline embolization device was implanted. Follow-up examinations presented a completely occluded additional caudal limb and a decreasing aneurysm size. No clinically adverse events occurred within twenty-fourmonth post-treatment. Therefore, sole flow diversion was a feasible treatment option in this case.
\end{abstract}

Keywords: fenestrated cerebral artery, cavernous aneurysm, flow diversion, pipeline device

\section{Introduction}

Fenestration of intracranial arteries is a rare but well-known phenomenon. It is defined as blood vessel duplication with split lumen that reunite downstream of the division. Incidences range up to $12.9 \%$ and, depending on cohort studies, affect basilar artery or anterior cerebral artery most commonly. ${ }^{1,4}$ Intracranial fenestration of internal carotid arteries (ICA) is extremely rare with less than $2 \%$ of all cerebral artery fenestrations. ${ }^{18}$ The etiology of arterial fenestration, especially of cerebral arteries, is probably based on insufficient fusion of fetal vessels. ${ }^{5}$ Moreover, aneurysms seem to appear at these atypical vessel bifurcations, probably flowassociated due to hydromechanical stress on vessel layers ${ }^{6}$ and can be found in up to $60.5 \%$ of all cerebral artery fenestrations. ${ }^{1}$ For ICA fenestrations with flowassociated aneurysms, there are only a handful of reports describing treatment via craniotomy and neurosurgery, interdisciplinary approaches or with an interventional treatment. $^{10,18}$ To the best of our knowledge, we here present the first case with flow diversion as the sole treatment strategy for this extremely rare anomaly.

\section{Case Presentation}

The patient had suffered from migraine for years. Within the course of a planned change of medication, a cranial magnetic resonance tomography was carried out which presented an incidental aneurysm of the left ICA. For further consultation, she was admitted to the outpatient clinic of the Leipzig University Neurosurgical Department. 
A clinical examination revealed, apart from around three to four episodes of nausea and headache per month, no neurological deficits. She had no history of intracranial bleeding. A digital subtraction angiography of cerebral vessels (DSA) was carried out and revealed a fenestration of the left ICA, segment C7 (subsegment 1), ${ }^{12}$ confirming the aneurysm (Figure 1). No further intracranial vascular pathology was diagnosed. Considering all possible treatment options in an interdisciplinary neurovascular board, a non-surgical procedure was indicated and planned electively. Due to the origination of the ophthalmic artery from the cranial limb, flow diverter implantation was indicated here in order to prevent too rapid occlusion or blood flow reduction.
Hence, endovascular microcatheterization was employed. Entry point was the right femoral artery. The pipeline device (PED $3.5 \times 25 \mathrm{~mm}$, Medtronic, California) was implanted into the cranial limb of the ICA fenestration. Directly postimplantation, and apart from an observed stagnation of contrast within the aneurysm (eclipse sign), there was no reduction in blood flow distal to the flow diverter (Figure 2A and E). Periinterventionally, the patient was started on antithrombotic therapy with ASA and ticagrelor. Afterwards she was monitored at our operative intensive care unit overnight. No neurological deficit occurred; a post-interventional cranial CT scan was without evidence of bleeding, infarction or hydrocephalus. The patient was discharged from hospital after four days.
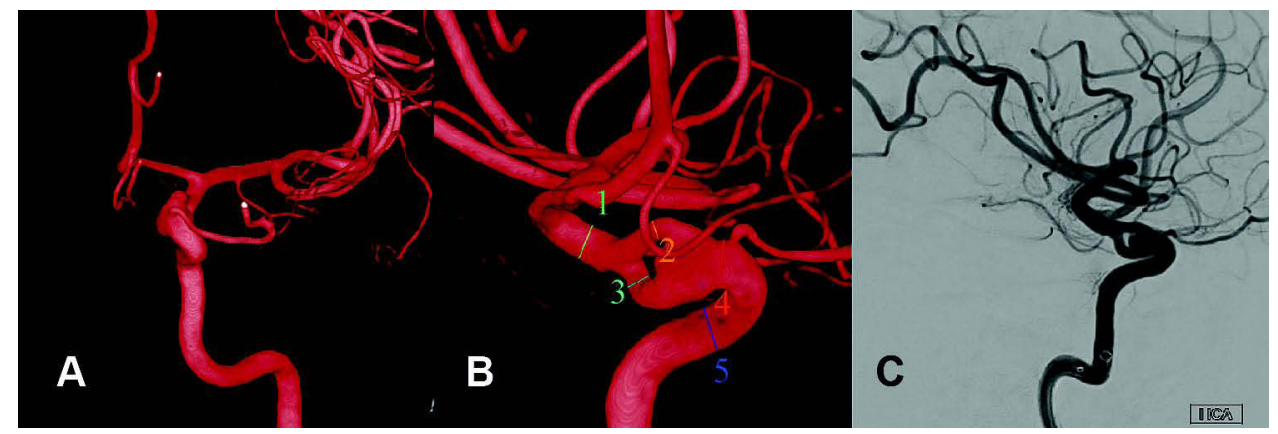

Figure I 3D-reconstruction (A and B) and lateral view in digital subtraction angiography (C) of left ICA presenting the fenestration with a flow-associated aneurysm within the proximal bifurcation. Vessel lumen diameters in $\mathrm{mm}$ as depicted in $\mathrm{b}: \mathrm{I}-2.77 ; 2-1.5 \mathrm{I} ; 3-1.90 ; 4-3.73 ; 5-3.46$.

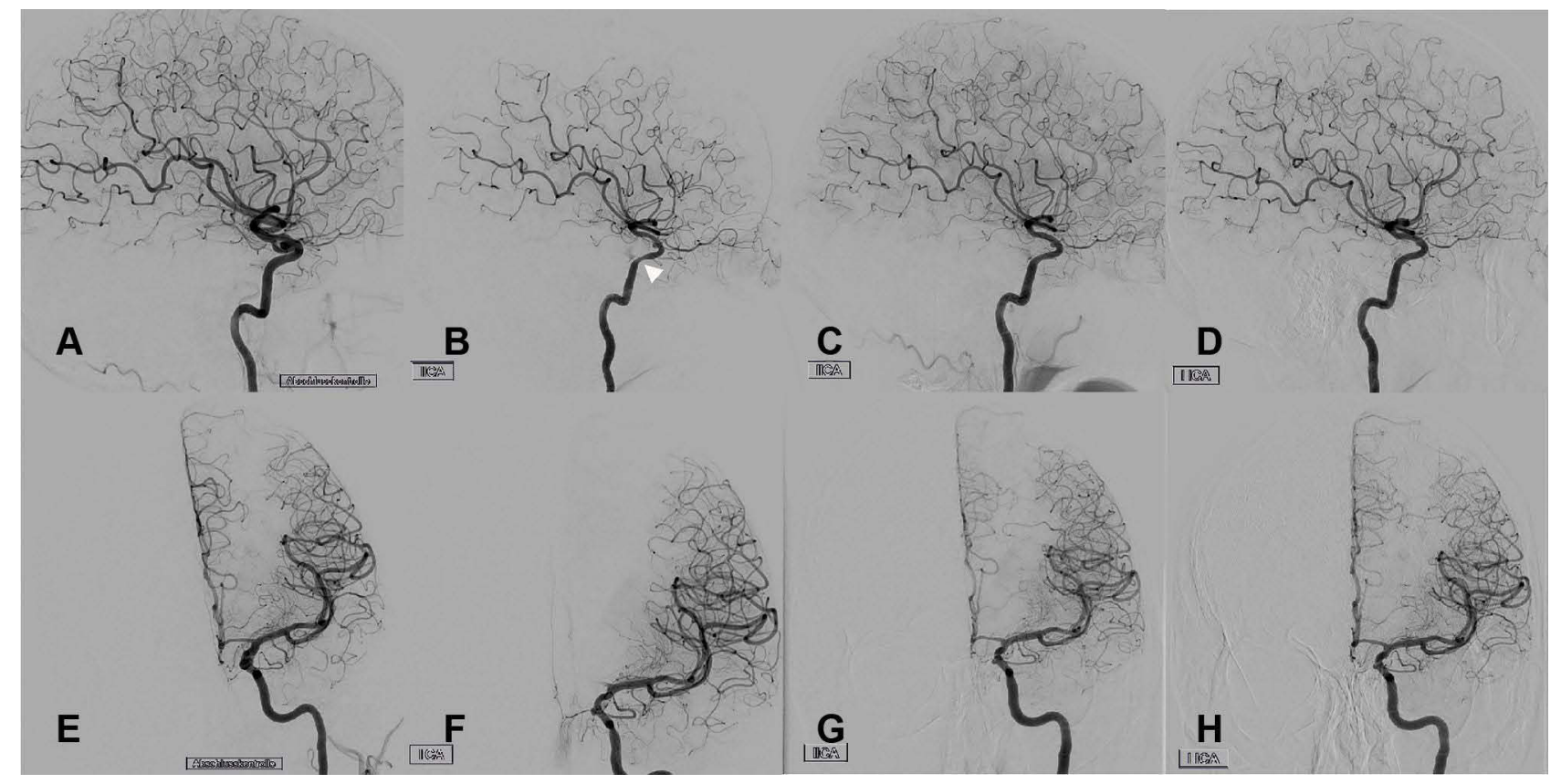

Figure 2 Angiographic follow-up via digital subtraction angiography of left ICA. (A and E) Directly after implantation of the pipeline device; (B and F) after three months; (C and $\mathbf{G}$ ) after twelve months; ( $\mathbf{D}$ and $\mathbf{H}$ ) after twenty-four months. Note the transient relative hypoperfusion of the left anterior cerebral artery via left ICA three months post-interventionally that completely reversed during next follow-ups accompanied by transient intimal hyperplasia (white arrowhead). 
Follow-up examinations via DSA were carried out three, twelve and twenty-four months post implantation of the pipeline device. Exemplary pictures are presented in Figure 2. The first follow up revealed an already completely occluded caudal fenestration branch accompanied by regressive aneurysm size, proximal intimal hyperplasia within the pipeline device, reduced ICA lumen diameter distal to the pipeline device (compare Figure 2A and B) and a hypoperfusion of the A1segment of the left anterior cerebral artery, compensated by cross-over perfusion from the right ACI (Figure 3). The next two follow-up examinations presented a decreasing size of the flow-associated aneurysms, a full regression of the intimal hyperplasia and, more importantly, the physiological reperfusion of the left anterior cerebral artery via left ICA. The dual antithrombotic therapy was deescalated to ASA monotherapy twelve-month post-implantation. Neurological deficits were absent at all times.

\section{Discussion}

We here present the first case of ICA fenestration with a flow-associated aneurysm that was treated with flow diversion only. Within a follow-up over two years, the additional ICA branch occluded completely, and the aneurysm was regressive in size. No clinically relevant adverse events were recorded.

The ICA normally appears at the 24th day of embryonic development, branches off into an anterior and posterior division 4 days later and, at a later stage, gives rise to the anterior and middle cerebral artery. ${ }^{16}$ Regarding the complete cerebral arterial vessel system, persistent artery fenestrations are found in 6.6 to $24.0 \%$ of all patients and appear to be extremely rare involving the ICA. ${ }^{8,18,19}$ Therapeutic options, especially when flow-associated aneurysms are involved, include craniotomy and neurosurgery, mostly in ruptured flow-associated aneurysms, and endovascular coiling for unruptured aneurysms associated with ICA fenestrations. ${ }^{18}$ There is one case report of combined coiling and flow diversion for a patient with multiple flow-associated aneurysms and a fenetrated ICA, but clinical and radiological follow-up is not given. ${ }^{10}$ The fenestration was located at segments C5 and C6 (ophthalmic part), and the aneurysms were situated very similar to the presented case within the proximal bifurcation and posterior limb of the ICA fenestration.

Concerning the management of intracranial aneurysms, flow diversion is of increasing importance. The main strategy includes altering the blood flow, especially diminishing blood exchange between the aneurysm and its parent vessel, and thereby promoting neointimal overgrowth, ${ }^{9,13}$ resulting in an exclusion of aneurysms from the cerebral blood circulation. Since the first multi-center trial in 2011 (PITA trial ${ }^{17}$ ), presenting favorable treatment results for unruptured aneurysms or aneurysms with failed previous therapy, evidence for elective flow diversion in intracranial aneurysm therapy is rising. ${ }^{3}$ Sufficient occlusion rates were also achieved for ruptured aneurysms, ${ }^{2}$ even considering new techniques to address the issue of antithrombotic therapy in acute subarachnoid hemorrhage. ${ }^{14,15}$ Concerning altered cerebral perfusion after implantation of a flow diverting device, risk factors include smoking and aneurysm size, ${ }^{11}$ but late ischemic events seem to be rare. ${ }^{7}$ In our case, the transient hypoperfusion of the A1 segment of the treated side was

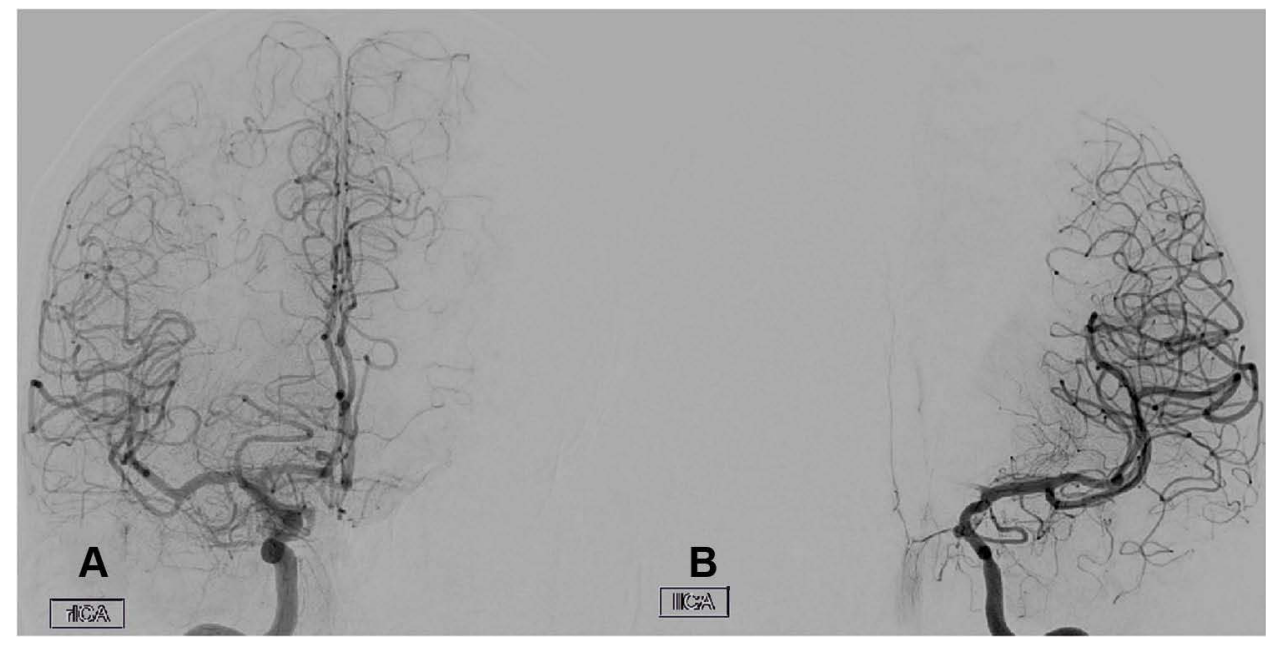

Figure 3 Coronal view of both ICAs via digital subtraction angiography three months after pipeline device implantation presenting left anterior cerebral artery hypoperfusion from left ICA (B) that is compensated via crossflow from right ICA (A). 
compensated by crossflow from the right ICA and normalized within twelve-month post-implantation. No neurological deficit occurred during this period.

\section{Conclusion}

Stand-alone flow diversion might be a feasible treatment option for cerebral artery fenestrations with flowassociated aneurysms. The risks of cross-over limb occlusion and (transient) cerebral hypoperfusion have to be kept in mind for these patients.

\section{Abbreviations}

DSA, digital subtraction angiography; ICA, internal carotid artery.

\section{Ethical and Institutional Approval}

An ethical or institutional approval was not required to publish the case details. Additionally, the patient granted written informed consent to report the case.

\section{Written Consent}

Written informed consent to report the case was obtained from the patient.

\section{Acknowledgment}

We thank the patient for permission to report her case.

\section{Disclosure}

The authors declare no conflict of interest.

\section{References}

1. Bożek P, Pilch-Kowalczyk J, Kluczewska E, Zymon-Zagórska A. Detection of cerebral artery fenestrations by computed tomography angiography. Neurol Neurochir Pol. 2012;46(3):239-244. doi:10.5114/ ninp.2012.29132

2. Cagnazzo F, Di Carlo DT, Cappucci M, Lefevre P-H, Costalat V, Perrini P. Acutely ruptured intracranial aneurysms treated with flow-diverter stents: a systematic review and meta-analysis. AJNR Am J Neuroradiol. 2018;39(9):1669-1675. doi:10.3174/ajnr.A5730

3. Chancellor B, Raz E, Shapiro M, et al. Flow diversion for intracranial aneurysm treatment: trials involving flow diverters and long-term outcomes. Neurosurgery. 2020;86(Suppl 1):S36-S45. doi:10.1093/ neuros/nyz345

4. Cooke DL, Stout CE, Kim WT, et al. Cerebral arterial fenestrations. Interv Neuroradiol. 2014;20(3):261-274. doi:10.15274/INR-201410027
5. Dey M, Awad IA. Fenestration of supraclinoid internal carotid artery and associated aneurysm: embryogenesis, recognition, and management. World Neurosurg. 2011;76(6):592.e1-5. doi:10.1016/j. wneu.2011.04.019

6. Finlay HM, Canham PB. The layered fabric of cerebral artery fenestrations. Stroke. 1994;25(9):1799-1806. doi:10.1161/01. STR.25.9.1799

7. Guédon A, Clarençon F, Di Maria F, et al. Very late ischemic complications in flow-diverter stents: a retrospective analysis of a single-center series. J Neurosurg. 2016;125(4):929-935. doi:10.3171/ 2015.10.JNS15703

8. Haase A, Schob S, Quäschling U, Hoffmann K-T, Meixensberger J, Nestler U. Epidemiologic and anatomic aspects comparing incidental and ruptured intracranial aneurysms: a single centre experience. J Clin Neurosci. 2020;81:151-157. doi:10.1016/j.jocn.2020.09.048

9. Hong B, Wang K, Huang Q, et al. Effects of metal coverage rate of flow diversion device on neointimal growth at side branch ostium and stented artery: an animal experiment in rabbit abdominal aorta. Neuroradiology. 2012;54(8):849-855. doi:10.1007/s00234-0110984-6

10. Jha N, Crockett MT, Singh TP. Unusual right internal carotid artery supraclinoid segment fenestration associated with multiple aneurysms treated with flow diversion and coiling. BMJ Case Rep. 2018;2018: bcr-2018.

11. Kim J, Li Y, Ahmed A. Predictors of impaired cerebral perfusion after flow diversion therapy. World Neurosurg. 2019;127:e556-e560. doi:10.1016/j.wneu.2019.03.203

12. Lasjaunias PL. Segmental identity and vulnerability in cerebral arteries. Interv Neuroradiol. 2000;6(2):113-124. doi:10.1177/ 159101990000600205

13. Lieber BB, Gounis MJ. The physics of endoluminal stenting in the treatment of cerebrovascular aneurysms. Neurol Res. 2002;24(Suppl 1):S33-42. doi:10.1179/016164102101200014

14. Lobsien D, Clajus C, Behme D, et al. Aneurysm treatment in acute SAH with hydrophilic-coated flow diverters under single-antiplatelet therapy: a 3-center experience. AJNR Am J Neuroradiol. 2021;42 (3):508-515. doi:10.3174/ajnr.A6942

15. Manning NW, Cheung A, Phillips TJ, Wenderoth JD. Pipeline shield with single antiplatelet therapy in aneurysmal subarachnoid haemorrhage: multicentre experience. $J$ Neurointerv Surg. 2019;11 (7):694-698. doi:10.1136/neurintsurg-2018-014363

16. Menshawi K, Mohr JP, Gutierrez J. A functional perspective on the embryology and anatomy of the cerebral blood supply. $J$ Stroke. 2015;17(2):144-158. doi:10.5853/jos.2015.17.2.144

17. Nelson PK, Lylyk P, Szikora I, Wetzel SG, Wanke I, Fiorella D. The pipeline embolization device for the intracranial treatment of aneurysms trial. AJNR Am J Neuroradiol. 2011;32(1):34-40. doi:10.3174/ ajnr.A2421

18. Ole Nöldeke J, Lemcke J, Gräwe A, Gölz L, Gutowski P. An interdisciplinary approach to the treatment of a complex infraclinoidal internal carotid artery aneurysm. Neuroradiol J. 2019;32(5):376-381. doi:10.1177/1971400919845621

19. van Rooij SBT, Bechan RS, Peluso JP, Sluzewski M, van Rooij WJ. Fenestrations of intracranial arteries. AJNR Am J Neuroradiol. 2015;36(6):1167-1170. doi:10.3174/ajnr.A4236 


\section{Publish your work in this journal}

The International Medical Case Reports Journal is an international, peer-reviewed open-access journal publishing original case reports from all medical specialties. Previously unpublished medical posters are also accepted relating to any area of clinical or preclinical science. Submissions should not normally exceed 2,000 words or 4 published pages including figures, diagrams and references. The manuscript management system is completely online and includes a very quick and fair peer-review system, which is all easy to use. Visit http://www.dovepress.com/testimonials.php to read real quotes from published authors. 